\title{
CORRIGENDUM
}

\section{Chronic idiopathic myelofibrosis expressing a novel type of TEL-PDGFRB chimaera responded to imatinib mesylate therapy}

K Tokita, K Maki, J Tadokoro, Y Nakamura, Y Arai, K Sasaki, M Eguchi-Ishimae, M Eguchi and K Mitani

Leukemia (2008) 22, 672; doi:10.1038/sj.leu.2405099

Correction to: Leukemia (2007) 21, 190-192. doi:10.1038/sj.leu.2404397

Since the publication of this paper, it has been identified by the authors that there is an error in the amino-acid sequence of the chimaeric protein in Figure 2.
The authors apologize for any inconvenience caused.

The correct Figure 2 is shown below:

TEL
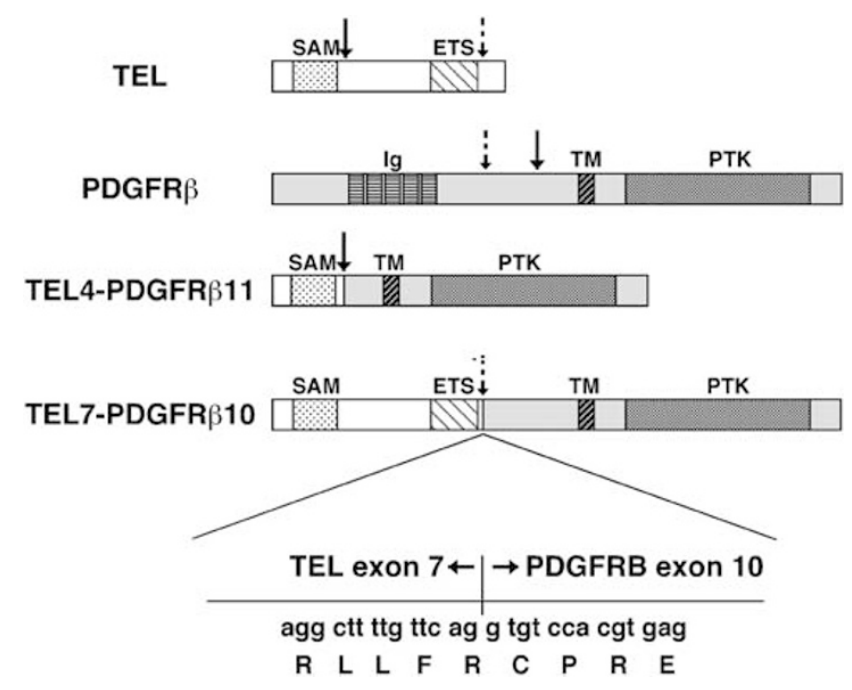

Figure 2 Structure of novel TEL-PDGFR $\beta$ fusion protein. Schematic diagrams of TEL, PDGFR $\beta$ and previously reported (TEL4-PDGFR $\beta 11$ ) and novel (TEL7-PDGFR $\beta 10$ ) TEL-PDGFR $\beta$ chimaeric proteins are depicted. The nucleotides and amino-acid sequences at the TEL7-PDGFR $\beta 10$ fusion junction are shown below. The dotted and solid arrows indicate the breakpoints in TEL7-PDGFR $\beta 10$ and TEL4-PDGFR $\beta 11$, respectively. Abbreviations: SAM, sterilealpha-motif domain; ETS, ETS domain; Ig, immunoglobulin-like domain; TM, transmembrane region; PTK, protein-tyrosine kinase domain. 